\title{
A Comparitive Study of Laying Open of Wound Vs Primary Closure In Fistula in Ano
}

\author{
Sundar Prakash $\mathrm{S}^{1}$, Saravanan P S $\mathrm{S}^{2}$, Chandra Prabha $\mathrm{J}^{3}$ \\ Assistant Professor, Department of General Surgery, Meenakshi Medical College and Research Institute, \\ Kanchipuram. \\ Professor, Department of General Surgery, Meenakshi Medical College and Research Institute, Kanchipuram. \\ Final year PG, Department of Physiology, Department of General Surgery, Meenakshi Medical College and \\ Research Institute, Kanchipuram.
}

\section{Introduction}

Fistula-in-ano is one of the common ano-rectal disorder which causes appreciable morbidity and inconvenience to the patient. Fistula is a Latin word which means pipe.

Fistula-in-ano is a preventable disease provided the perianal or perirectal suppurations are treated on time and in a correct manner. The common pathogenesis is the bursting open of an acute or inadequately treated ano-rectal abscess.

The location of the diseased part makes the patient refrain from early consultation and this is the main cause for the delay in treating the patients with perianal suppurations. The more important second factor is that a significant percentage of these diseases persist or recur when the right modality of treatment is not adopted or when the postoperative care is inadequate.

The chronicity with its annoying symptoms like soiling of the undergarments and repeated abscess formation makes an otherwise healthy and active person lose his earning capacity with lowered self-confidence.

The categorization of fistula-in-ano is based on the location of the fistula in relation to the anal sphincters. According to Park's Classification it is Inter-sphincteric, Trans-sphincteric, Supra-sphincteric or Extra-sphincteric.

The main principles of management are closure of internal opening of the fistulous tract, drainage of infection or necrotic tissue, removal of the tract and sphincter preservation.

Different surgical techniques have been described in literature from time to time like Park's fistulectomy, fistulectomy with primary closure, two-stage fistulotomy, primary fistulectomy with closure of internal ostium, fistulotomy with primary repair of the sphincter, endorectal advancement flaps, ano-cutaneous advancement flaps, repair of fistula using fibrin adhesive glue and re-routing the fistula.

Open fistulectomy though considered as the standard treatment for fistula-in-ano, fistulectomy with primary closure has its merits of short hospital stay, early wound healing and lower costs.

\section{Aims And Objectives}

To study the outcome of primary wound closure over non closure of wound after fistulectomy.

\section{Materials And Methods}

This is a randomized comparative prospective study of 52 cases of fistula-in-ano presenting at the surgical OPD of Meenakshi Medical College and Research Institute, out of which 35 cases were treated with fistulectomy only and 17 cases with fistulectomy with primary wound closure during the period of March 2012 to February 2014.

A detailed history, thorough clinical examination including per rectal examination were done in all the cases. All patients had undergone routine blood investigations, Chest X-Ray and ECG prior to surgery. In doubtful cases CT scan and MRI were done.

\section{Inclusion criteria}

1. All types of fistula-in-ano

2. Any age group

3. Any gender

\section{Exclusion criteria}

All patients of fistula-in-ano with

1. Carcinoma

2. Irradiation 
3. Chron's disease

4. Active sepsis

5. Patients not willing

The 52 patients in our study were divided into 2 groups.

Group I: Open Fistulectomy

Group II: Fistulectomy with primary closure

\section{Techniques of surgery}

fistulectomy

After getting a written consent from the patient and relative, under spinal anaesthesia, patient was put in Lithotomy position. The external and internal openings were identified and probed. The fistulous tract was then excised and the wound after achieving haemostasis was left open and was packed with gauze.

\section{Fistulectomy with primary closure of the wound}

After fistulectomy the wound was closed in layers, using catgut for subcutaneous layer and nonabsorbable suture material (Ethilon) for skin. The sutures were removed on the seventh postoperative day. Selection of cases for primary closure is important. High anal fistula is not suitable for primary closure. This method is readily applied to simple direct fistulae.

\section{Age distribution}

\section{Results And Observations}

In our study the age of the patient varied from 21-70 years. Majority of the patients were between 21 and 40 years of age as shown in the Table 1 . All the patients who had undergone primary closure of wound were young, ranging from 21 to 40 years of age.

Table 1

\begin{tabular}{|l|l|l|l|l|}
\hline Age & Group I & Group II & Total & Percentage (\%) \\
\hline $21-30$ & 12 & 6 & 18 & 35 \\
\hline $31-40$ & 5 & 12 & 17 & 33 \\
\hline $41-50$ & 0 & 10 & 10 & 18 \\
\hline $51-60$ & 0 & 4 & 4 & 8 \\
\hline$>60$ & 0 & 3 & 3 & 6 \\
\hline Total & $\mathbf{1 7}$ & $\mathbf{3 5}$ & $\mathbf{5 2}$ & \\
\hline
\end{tabular}

In our study the ratio of male:female was 4:1. Out of 41 males, 12 had undergone primary closure and out of 11 females 5 had undergone primary closure (Table 2).

Table 2

\begin{tabular}{|l|l|l|}
\hline \multirow{2}{*}{ Group } & Sex & Female \\
\cline { 2 - 3 } & Male & 6 \\
\hline \multirow{3}{*}{ Group I } & 29 & $55 \%$ \\
\cline { 2 - 3 } & $71 \%$ & 5 \\
\hline \multirow{2}{*}{ Group II } & 12 & $45 \%$ \\
\cline { 2 - 3 } & $29 \%$ & 11 \\
\hline \multirow{2}{*}{ Total } & 41 & $21 \%$ \\
\cline { 2 - 3 } & $79 \%$ & \\
\hline
\end{tabular}

\section{Causes for fistula formation}

In majority of cases in our study, the major cause for fistula-in-ano wasanorectal abscess, inadequately drained abscess (I\&D) or history of any anorectal surgeries like haemorrhoidectomy, lateral sphincterotomy etc. (Table 3).

Table 3

\begin{tabular}{|l|l|l|l|}
\hline \multirow{3}{*}{ Group } & Anorectal pathology & \multicolumn{2}{|l|}{} \\
\cline { 2 - 4 } & Ano-rectal abscess & $\begin{array}{l}\text { Inadequate drainage } \\
\text { (I\&D) }\end{array}$ & Previous surgery \\
\hline \multirow{3}{*}{ Group I } & 18 & 12 & 5 \\
\cline { 2 - 4 } & $52 \%$ & $34 \%$ & $14 \%$ \\
\hline \multirow{3}{*}{ Group II } & 10 & 7 & 0 \\
\cline { 2 - 4 } & $59 \%$ & $41 \%$ & 0 \\
\hline \multirow{2}{*}{ Total } & 28 & 19 & 5 \\
\cline { 2 - 4 } & $54 \%$ & $37 \%$ & $10 \%$ \\
\hline
\end{tabular}




\section{Symptoms}

The main presenting symptoms in our study were discharge, swelling and pain. $86 \%$ of the patients had discharge, 25\% had swelling and 19\% had pain as shown in Table 4 and Graph 1.

Table 4

\begin{tabular}{|l|l|l|l|}
\hline \multirow{2}{*}{ Group } & Symptoms & Swelling & Pain \\
\cline { 2 - 4 } & Discharge & 11 & 6 \\
\hline \multirow{3}{*}{ Group I } & 32 & $31 \%$ & $17 \%$ \\
\cline { 2 - 4 } & $91 \%$ & 2 & 4 \\
\hline \multirow{3}{*}{ Group II } & 13 & $12 \%$ & $24 \%$ \\
\cline { 2 - 4 } & $77 \%$ & 13 & 10 \\
\hline \multirow{2}{*}{ Total } & 45 & $25 \%$ & $19 \%$ \\
\cline { 2 - 4 } & $86 \%$ & & \\
\hline
\end{tabular}

Graph 1

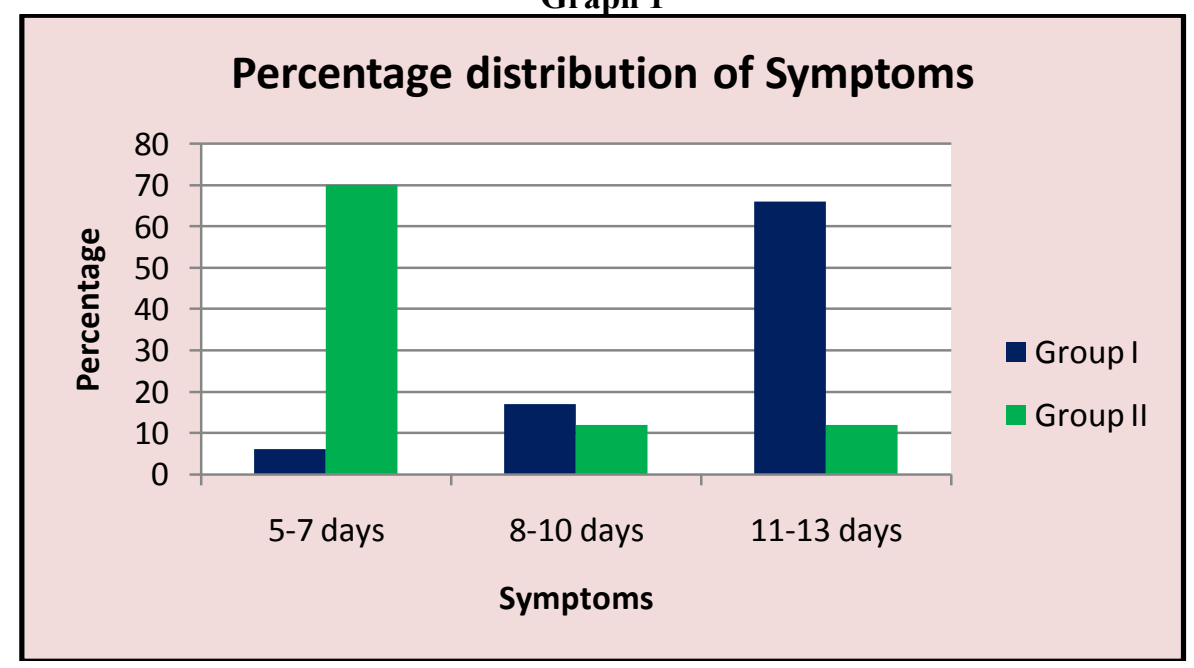

Fistulous opening

Internal opening

Proctoscopic examination revealed all the internal openings in our study.

\section{External opening}

In our study group of 52 patients, 13 had anterior and 39 had posterior openings (Table 5).

Table 5

\begin{tabular}{|l|l|l|}
\hline \multirow{2}{*}{ Group } & External opening \\
\cline { 2 - 3 } & Anterior & Posterior \\
\hline \multirow{3}{*}{ Group I } & 10 & 25 \\
\cline { 2 - 3 } & $29 \%$ & $71 \%$ \\
\hline \multirow{2}{*}{ Group II } & 3 & 14 \\
\cline { 2 - 3 } & $18 \%$ & $82 \%$ \\
\hline \multirow{2}{*}{ Total } & 13 & 39 \\
\cline { 2 - 3 } & $25 \%$ & $75 \%$ \\
\hline
\end{tabular}

\section{Postoperative pain}

In our study, out of 35 patients in Group I, 28 had postoperative pain ranging from mild to severe pain with a pain score of 9.8 and in those who had undergone primary closure only 13 had pain. The pain index for them was only 3.3 (Table 6 and Graph 2)). To relieve the pain Injection Diclofenac sodium IM was used in the first 24 hours and repeated whenever necessary in all the patients.

Table 6

\begin{tabular}{|l|l|l|}
\hline Group & Postoperative pain & Pain index \\
\hline Group I & 28 & 9.8 \\
\hline Group II & 13 & 3.3 \\
\hline
\end{tabular}


Graph 2

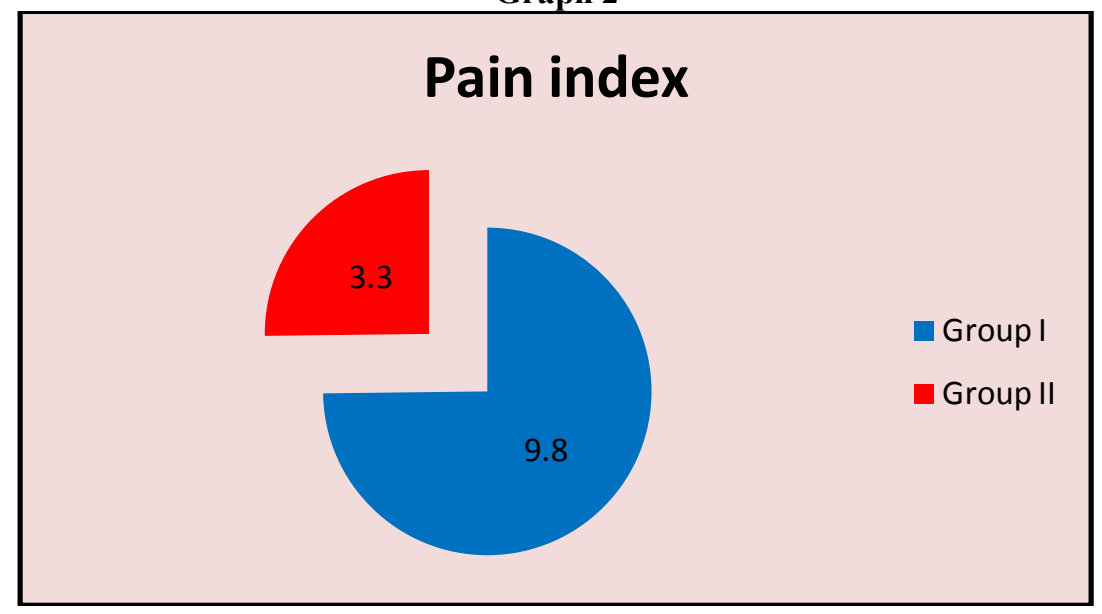

\section{Wound healing time}

In our study, majority of the patient's wound healed in 3-4 weeks in those who underwent open fistulectomy, whereas in the primary closure method the wounds healed in 1-3 weeks as shown in Table 7 and Graph 3.

Table 7

\begin{tabular}{|c|c|c|c|c|c|c|}
\hline \multirow[t]{2}{*}{ Group } & \multicolumn{6}{|c|}{ Period of wound healing } \\
\hline & $1 \mathbf{w k}$ & 2 wks & 3 wks & 4 wks & 5 wks & $>5$ wks \\
\hline Group I & $0 \%$ & $0 \%$ & $14 \%$ & $66 \%$ & $17 \%$ & $3 \%$ \\
\hline Group II & $36 \%$ & $29 \%$ & $29 \%$ & $6 \%$ & $0 \%$ & $0 \%$ \\
\hline
\end{tabular}

Graph 3

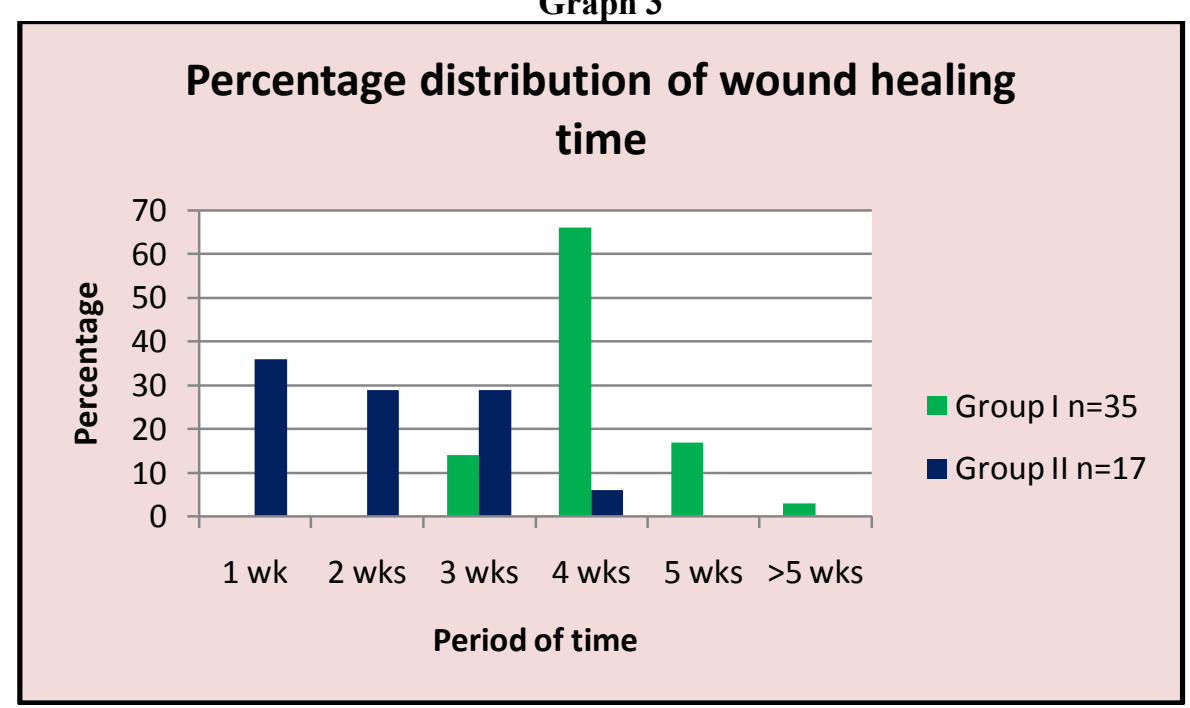

\section{Complications}

Retention of urine was the commonest complication in the immediate postoperative period. Apart from that 2 patients had haemorrhage. Recurrence of fistula occurred in 5 patients. The Table 8 explains this.

Table 8

\begin{tabular}{|l|l|l|l|l|l|}
\hline \multirow{2}{*}{ Group } & Complication & Retention of urine & Incontinence & Stricture & Recurrence \\
\cline { 2 - 6 } & H'age & 10 & 0 & 0 & 4 \\
\hline \multirow{3}{*}{ Group I } & 2 & $29 \%$ & $0 \%$ & $0 \%$ & $11 \%$ \\
\cline { 2 - 6 } & $6 \%$ & 1 & 0 & 0 & 1 \\
\hline \multirow{2}{*}{ Group II } & 0 & $6 \%$ & $0 \%$ & $0 \%$ & $6 \%$ \\
\cline { 2 - 6 } & $0 \%$ & & 0 & \\
\end{tabular}


Graph 4

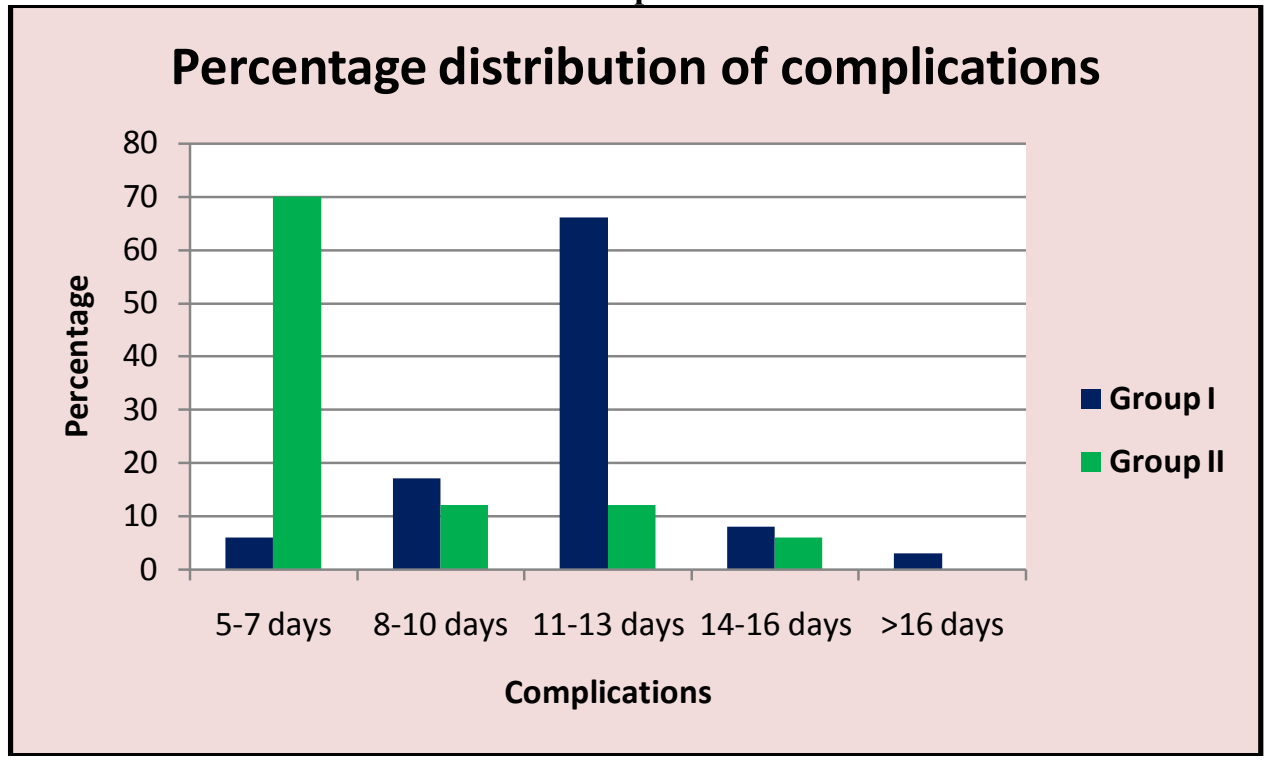

\section{Period of hospital stay}

In our study those patients who had undergone open fistulectomy stayed in the hospital for a longer period, whereas those with primary closure got discharged in the first week itself (Table 9 and Graph 5).

Table 9

\begin{tabular}{|c|c|c|c|c|c|}
\hline \multirow{2}{*}{ Group } & \multicolumn{5}{|c|}{ No of hospital days } \\
\hline & $5-7$ & 8-10 & 11-13 & 14-16 & $>16$ \\
\hline \multirow{2}{*}{ Group I } & 2 & 6 & 23 & 3 & 1 \\
\hline & $6 \%$ & $17 \%$ & $66 \%$ & $8 \%$ & $3 \%$ \\
\hline \multirow[t]{2}{*}{ Group II } & 12 & 2 & 2 & 1 & $\mathbf{0}$ \\
\hline & $70 \%$ & $12 \%$ & $12 \%$ & $6 \%$ & $0 \%$ \\
\hline
\end{tabular}

Graph 5

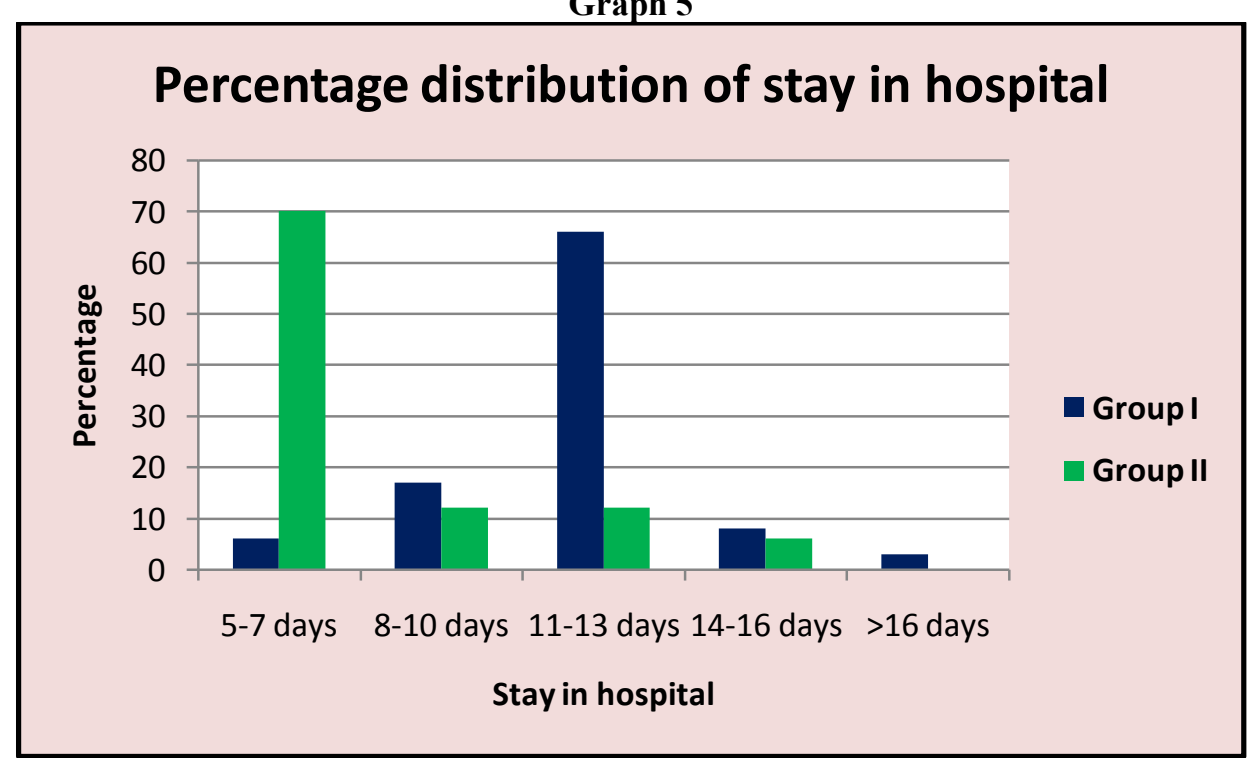

\section{Discussion}

Fistula-in-ano is a condition that has been described from the beginning of medical history. But the treatment still poses a surgical problem. Many authors have presented new operative techniques and case series to minimise the recurrence rate and incontinence. But the treatment remained a challenging job for the surgeon. The patient satisfaction after surgical treatment is not associated with age, gender, previous fistula surgery, type of fistula or time of surgery. But it depends upon factors like postoperative hospital stay, postoperative pain, return to normal activity, wound healing time and most importantly the recurrence of the disease. The principles 
of management are drainage of infection and eradication of fistulous tract with preservation of sphincter function.

In our study 52 cases of anal fistula were studied, out of which 35 cases were treated with open fistulectomy and 17 cases were treated withfistulectomy followed by primary closure of the wound.

In a study by Shahbaz C M et al, the peak incidence of fistula-in-ano was 21-40 years of age group and the male:female ratio was 4:1. In our study also the peak age incidence was 21-40 years with a male:female ratio of $4: 1$.

In a study by Vasilevsky et al, the cause for fistula-in-ano was anorectal abscess (21\%), I\&D (39\%) and previous surgery (11\%). In our study of 52 cases, the causes were anorectal abscess (54\%), I\&D (37\%) and previous rectal surgeries $(10 \%)$. This clearly proves that in our place the major cause was anorectal abscess owing to poor hygiene of the patients, as most of them are from poor socio-economic group.

In a study by Vasilevsky et al, the predominant symptom was perianal discharge. In our study also the predominant symptom was discharge followed by swelling and pain.

In a study by SushilDamor et al, the mean pain score for open fistulectomy group was 4.42 days and in primary closure group it was 2.77 days. But in our study the pain score for open fistulectomy group was 9.8 days and in primary closure group it was 3.3 days only. This clearly led to lesser usage of analgesics in the primary closure group.

In a study by SushilDamor et al, the average wound healing time for open fistulectomy cases was 21.24 days and for primary closure cases it was 8.24 days. In another study by Prakash $\mathbf{S}$ et al, the average healing period for open group was 5 weeks while in closure group it was 2 weeks. In our study, the average healing period for open fistulectomy cases was 4-5 weeks and for closure group it was 1-3 weeks. This is again in favour of primary closure of fistulectomy wound.

In a study by Starr et al showed $100 \%$ results with primary closure.no recurrence was seen. In another study by SushilDamor et al found to have $100 \%$ success rate in fistulectomy with primary closure. In a study by Prakash $\mathbf{S}$ et al showed 3 cases of recurrence out of 125 cases operated with primary closure. In another study by Poon Chi Ming et al showed 13.3\% of recurrence out of 135 cases. In our study out of 35 cases who underwent open fistulectomy 4 cases had recurrence whereas out of 17 cases who had primary closure only one case recurred. This is again in favour of primary closure than open fistulectomy.

In the same study by SushilDamor et al, the mean hospital stay by the primary closure group was 3.1 days. In another study by Toccaceli et al, the mean hospital stay was 3.2 days for the closure group. In another study by Prakash $\mathbf{S}$ et al the mean hospital stay was 5.2 days. In our study the mean hospital stay was 5.3 days and for the open fistulectomy group, 11.7 days. This clearly proves that primary closure patients stay for a shorter period in the hospital. This in turn led to lesser antibiotics use, less expenditure, early recovery and early return to work and lesser burden to the hospital staff.

The most important criteria in fistulectomy with primary closure is careful selection of patients. It also depends on the individual, the experience of the surgeon and the technique adopted by the surgeon. The most likely cause for recurrence is the failure to identify and excise the fistulous tract in total. Primary closure of wound should be done without tension.

\section{Conclusion}

The primary closure method of fistulectomy is a safe and feasible method and more effective in the management of fistula-in-ano in our study. was $4: 1$

The age incidence of anal fistulae in our study was between 21 and 40 years. The male:female ratio

The anorectal abscess was the major cause for fistula formation in our study.

The postoperative pain score in primary closure group is $60 \%$ lesser than the open fistulectomy group.

The average healing period for primary closure group is much lesser when compared to the other group.

The average hospital stay is $50 \%$ lesser in the primary closure group.

The recurrence rate was only $6 \%$ in primary closure group when compared to $11 \%$ recurrence rate in the open group.

The primary closure is a better alternative in the surgical management of fistula-in ano considering the benefits of lesser postoperative pain, early healing, early discharge, early return to normal activity, cost effective and lesser recurrence rate above the open fistulectomy. But it needs more prospective and randomized controlled trials to come to a conclusion because at this stage there is minimal literature and studies on this topic. 


\section{Bibliography}

[1]. Das A C, PrakashAgarwal, A comparative study of surgical techniques for fistula-in-ano, IJS; 1997 ; Vol 60 (4); $254-255$.

[2]. Goligher John, Surgery of the anus, rectum and colon, London, BailliereTindall; 1984; 178.

[3]. Parks A G, The pathogenesis and treatment of fistula-in-ano, British Medical Journal, 1961; Vol 1; $463-469$.

[4]. Prakash S, Lakshmi Ratan V, Gajendren V, Fistula-in-ano treatment by fistulectomy and primary closure reconstitution, Aust J Surg; Vol 55; 23-27.

[5]. Schwartz S I, Principles of Surgery, New York, McGraw Hill Inc, 1994; 1232-34.

[6]. Shahbaz C M, Ghazanfar A, Goraya A R, Comparative study of fistulectomy and fistulotomy with primary repair for low fistula-inano, Apr-jun 2002; Vol 8 (2); 87-90.

[7]. Starr W, Primary closure in proctology; 1953; Vol 14; 365.

[8]. Stuart T Ross, Fistula-in-ano, Techniques of colorectal surgery, 1988; Vol 68; 1417-26.

[9]. SushilDamor, AnisVohra, Hilton Patel, Praveen Kumar and JalpaBalat, A comparative study between primary closure method and open method of fistulectomy for fistula-in-ano, Int J Res Med; 2013; Vol 2 (1); 33-37.

[10]. Toccaceli S, Minervini S, Fistulectomy with closure by first intention in the treatment of perianal fistulae, Minerva Chir; Apr 1997; Vol 52 (4); 377-381.

[11]. Vasilevisky and Gordon, Results of treatment for fistula-in-ano, Dis.Col.Rectum, 1984; Vol 27; 543-597. 